
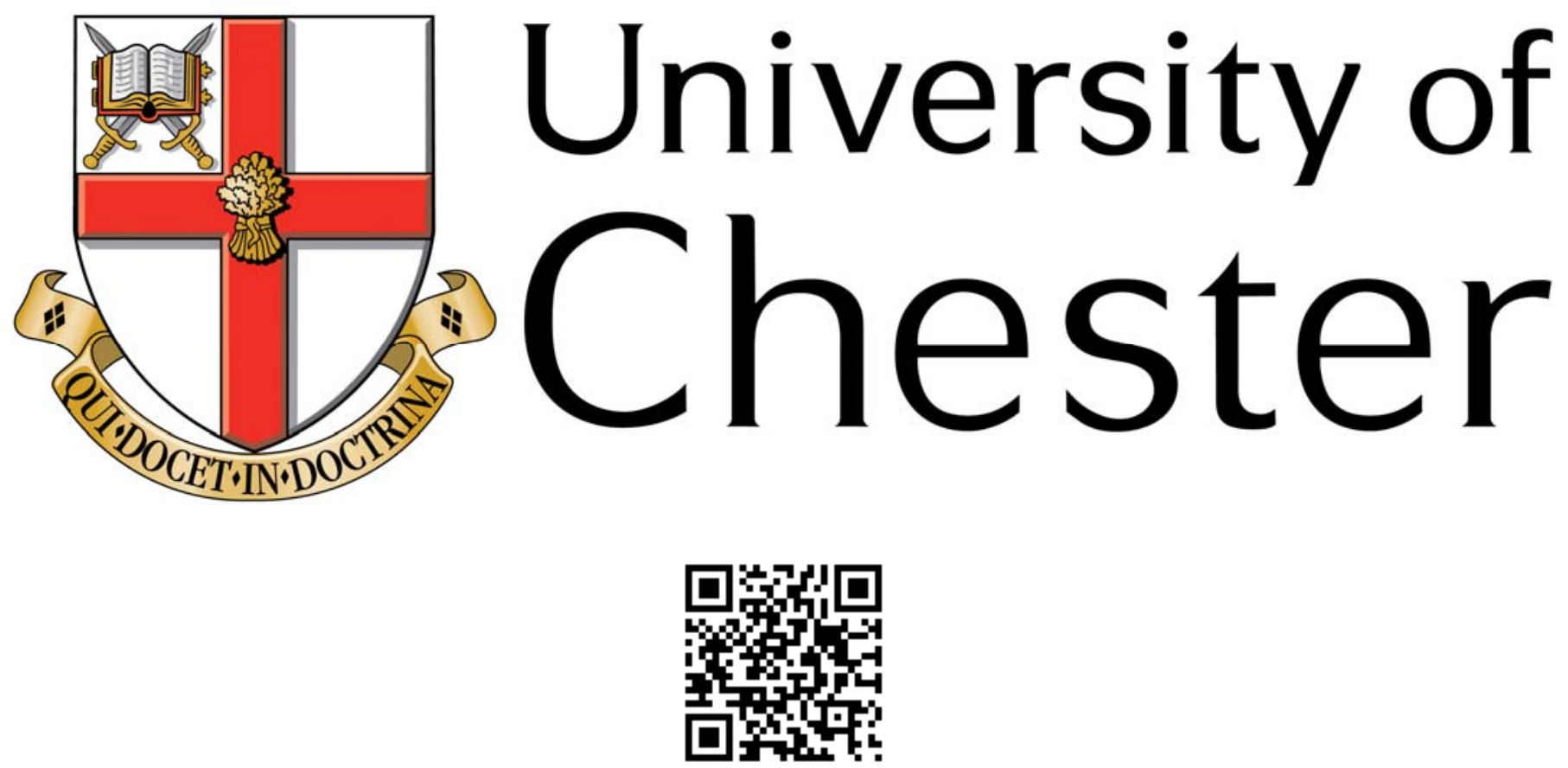

This work has been submitted to ChesterRep - the University of Chester's online research repository

\title{
http://chesterrep.openrepository.com
}

Author(s): Brooke Swash ; Nick Hulbert-Williams ; Ros Bramwell

Title: Unmet psychosocial needs in haematological cancer: A systematic review

Date: 2014. Appeared online 25 January 2014

Originally published in: Supportive Care in Cancer

Example citation: Swash, B., Hulbert-Williams, N., \& Bramwell, R. (2014). Unmet psychosocial needs in haematological cancer: A systematic review. Supportive Care in Cancer, 22(4), 1131-1141. http://dx.doi.org/10.1007/s00520-014-2123-5

Version of item: Authors' post-sprint

Available at: http://hdl.handle.net/10034/344398 


\section{Unmet psychosocial needs in haematological cancer: A}

\section{systematic review.}

Swash, B., ${ }^{1}$ Hulbert-Williams, N. ${ }^{1} \&$ Bramwell, R. ${ }^{1}$

${ }^{1}$ University of Chester, Department of Psychology, Chritchley Building, Parkgate Road, Chester, CH1 4BJ, UK

Correspondence: Brooke Swash, University of Chester, Department of

Psychology, Chritchley Building, Parkgate Road, Chester, CH1 4BJ, UK. Email:

b.swash@chester.ac.uk Phone: 07827807466 


\section{Abstract}

\section{Purpose}

Psychosocial need implies a desire or requirement for support that underlies a person's psychological, social and emotional wellbeing. This is not a new concept in the wider cancer literature, yet remains a relatively unexplored area in relation to haematological malignancies. The well recognised differences between haematological and other types of cancer diagnosis warrant further investigation to try and highlight the potential differences in the needs of this patient group.

\section{Method}

A systematic review of key online databases and psycho-oncology journals was conducted to identify papers that formally assessed unmet psychosocial needs in adults with a diagnosis of haematological cancer. The breadth of methodologies of included studies made a meta-analytical approach unfeasible, therefore studies were analysed using a narrative synthesis approach.

\section{Results}

18 studies were found to be relevant and a specific focus was placed on those papers that looked solely at participants with a haematological diagnosis. The key areas of need identified were: psychological need, notably fear of recurrence; information needs; and needs relating to both family and healthcare professionals. Fear of recurrence was the most commonly identified psychosocial need within this literature. 


\section{Conclusions}

The clinical implications of these findings highlight the need for more widespread access to psychological support for haematology patients and for more to be done to tackle patients' fears and concerns throughout the course of their illness. Assessment and identification of unmet needs is an important step enabling the development of clinical services that support and maintain psychological wellbeing through treatment and into survivorship.

Key words: review, needs, psychosocial, cancer, haematology, wellbeing 


\section{Background}

Patient-centred care is the gold standard for provision of healthcare in the UK [1]. Accordingly, care should no longer focus solely on delivery of medical treatment but also look to encompass the person's psychological and social needs in order to fully support that person's emotional and psychological wellbeing throughout their illness. The International Psychooncology Society (IPOS) recently published its Standard of Quality Cancer Care [2], a new quality standard to support the development and implementation of new clinical practice guidelines. In the UK, several cancer societies and charities have pledged to support the implementation of the new Standard of Quality Cancer Care that aims to integrate psychosocial support into routine cancer care, marking distress as the sixth vital sign after temperature, blood pressure, pulse, respiration and pain.

Psychosocial needs relate to a desire or requirement for help or support that underlies a person's emotional and psychological wellbeing [3, 4]. Unmet psychosocial needs are diverse and far reaching, having the potential to impact upon all areas of a person's life. Common examples include maintaining a sense of identity, body image, spirituality, relationships, social support mechanisms or the more practical issues related to a person's illness [5-7]. We know that needs of this nature are often underreported to clinicians [8] and therefore have the potential to 
be left unacknowledged. Levels of unmet psychosocial needs vary between individuals and are affected by a range of factors including sociodemographics variables. Younger, female, or unmarried patients; those with lower income, financial difficulties or who live in rural areas; and those with a previous or current history of psychiatric problems are all at risk of increased levels of need following cancer diagnosis $[9,10]$. Clinically, those requiring more intensive treatment and those diagnosed at a more advanced stage are also known to report greater need, with further variance observed across time from diagnosis to follow-up care [11].

The potential relevance of unmet psychosocial need becomes clear when we consider the impact that a negative psychological response to illness can have upon prognosis. The presence of anxiety, depression and a poor quality of life in cancer patients have all been found to negatively impact upon a variety of treatment outcomes such as adherence to treatment, motivation, ability to cope with the diagnosis and on prognosis [12], but the precise relationship between psychosocial needs and psychological morbidity in haematology is a topic that warrants further investigation.

The majority of published studies exploring unmet psychosocial needs in cancer patients recruit mixed cancer samples, with fewer focussing specifically on the needs of a single diagnostic group. While this may make the results more generalisable, needs that are specific to a particular diagnoses are difficult to distinguish, and the variation between 
methods also makes comparison between studies difficult [13]. In addition, mixed diagnosis studies typically over-recruit specific cancers, such as breast cancer, and under-recruit from others, haematological malignancies included. Where the existing literature serves an important function in highlighting the range of needs that are commonly found across different diagnoses, more focussed studies of the in-depth needs of specific patients groups is essential for individualised and holistic care.

The pathological differences inherent in haematological malignancies lead to particular psychosocial challenges. Both the manner and setting in which patients with haematological cancers are treated can differ from patients diagnosed with solid tumours [14]. Treatment is comparatively intensive and carries a high burden of illness that can impact upon a person's social, vocational and family functioning[15]. Despite being common cancers in the UK, there is substantially less psychosocial research into haematological cancers than solid tumours, possibly due to reduced public awareness and the comparatively short survival times of patients [16].

Psychosocial need is not a novel concept and, in general cancer samples, has received a fair amount of attention within the literature. Where understanding is not yet clear, is how well the psychosocial needs of haematology patients align with those of patients with solid tumours. In many cases, healthcare professionals who work with cancer patients will already be aware of the need for support as demonstrated by research in this area, however, a sound evidence base is required in order to highlight 
the on-going need [17]for psychosocial support services and to illustrate which needs above others require the greatest attention from clinicians. Consultations between patients and clinicians are typically short with an extra minute cited as being given for patients with psychosocial issues [18]. Clinical nurse specialists often fill the gap in terms of addressing patients' psychosocial concerns yet time pressures, the need to prioritise physical care and inequalities in access to this support nationwide [19] can mean that patient concerns in this area remain unaddressed. Having a clear understanding of the specific issues that are of greatest importance to their patient group will aid the identification of the most pertinent concerns within the limited time available.

\section{Review Objectives}

- To synthesise information about the type and prevalence of unmet psychosocial needs in haematological cancer;

- To highlight specific gaps within the current literature on unmet psychosocial need in haematological cancer;

- To create a clear understanding of the current evidence base relating to unmet need in haematology, upon which future research can build.

- Where possible, to make recommendations for clinical and service level developments to better meet the needs of this patient group 


\section{Methodology}

\section{Eligibility Criteria}

For the purposes of this review, an unmet psychosocial need is defined as the desire or requirement for help or support that, where not provided, may negatively impact upon a person's emotional and psychological wellbeing $[3,4]$. Included papers were required to state that they were measuring need, rather than simply patient concern, as concern does not necessarily equate to a desire for assistance to meet that need. Studies measuring quality of life or other psychological constructs such as depression only were also not deemed eligible for inclusion as they were deemed separate concepts to need.

For inclusion, papers had to assess unmet psychosocial needs in an adult sample (over 18 years of age) that was, at least in part, comprised of patients with a diagnosis of haematological cancer. There were no restrictions on the point at which needs were assessed or the time point at which needs were reported. All studies had to have been conducted within an appropriate healthcare or community setting: studies conducted within inpatient psychiatric or forensic institutions were not eligible for inclusion due to the potential bias to the cause of need. In addition, reporting of need had to be via self-report and not by a family member or healthcare professional.

Only published work was included in this review. This strategy was employed in order to reflect the information that would have been freely 
available to clinicians, healthcare professionals and researchers working in oncology.

There were no time restrictions placed upon date of publication.

\section{Search Methods}

The following databases of published literature were searched: CINAHL, MEDLINE, PsychINFO, Web of Knowledge, COCHRANE and DARE. All databases were searched using the same search string and searches were completed in January 2012. Additionally, the archives of key psychooncology journals (Psycho-Oncology, British Journal of Cancer and Journal of Psychosocial Oncology) were hand searched for any relevant papers. Reference lists of all articles accepted for inclusion within the review were searched for any additional relevant articles that had not come up within the original search.

\section{Data Collection and Analysis}

Of 14,549 titles identified by the searches, 18 were included in this review (see Fig.1). The inclusion process comprised four stages: the initial search results were de-duplicated and titles were visually screened for relevance; abstracts of remaining papers were compared to the inclusion criteria and those falling outside of their remit excluded; next, papers with suitable abstracts were read in full by both the reviewer and a second, independent reviewer to determine which were eligible for inclusion; finally, the reference lists of all included papers were screened for any further eligible studies that had not been found within the initial searches. 
For each paper, the following data was extracted:

- Basic study information: author, date, journal, identification number assigned.

- Sample description: recruitment, size, inclusion and exclusion criteria.

- Study design: timings, settings, interventions used.

- Outcome measures and statistical approaches used.

- Critical evaluation of the work: including limitations and implications for future research or clinical practice.

At the same time as data extraction was undertaken, each paper was assessed by one reviewer against a previously published quality checklist (Kmet et al., 2004) (see Box 1.). For each item in the checklist, a response and relating score was determined: yes (2), partial (1) or no (0). Provided that a study met all of the inclusion criteria then a poor quality score did not mean that the study was discounted, however knowledge of methodological limitations is important for understanding the implications and importance of each study in the synthesis.

Data was analysed using a narrative synthesis approach as variations in methodologies, samples and the lack of randomised controlled trials contained within the included papers prohibited the use of meta-analysis. 


\section{Results}

\section{Characteristics of Included Studies}

18 papers reporting the results of 17 separate studies were included within the review. For the purposes of this synthesis, studies were organised first according to their sample: either mixed cancer (that included haematology) sample or haematology only. Within these diagnostic groupings, papers were organised according to the time point at which need was assessed: diagnosis, treatment, end of treatment, follow-up care or mixed allowing for an in-depth view of need at the key stages of the cancer experience.

\section{Results of studies assessing unmet psychosocial need in mixed cancer samples}

\section{Diagnosis}

Two studies were identified that assessed unmet need at diagnosis in mixed cancer samples [20,21]. Boyes et al [20] compared patients whose completed measures were passed onto their clinician with a control group of patients whose measure was not seen by their clinician [20]. Unmet 
psychological needs were high in both groups ( 0.24 and 0.26 of participants respectively) but the type of psychological needs identified was not identified. A further study by Hawkins and colleagues assessed for unmet information needs only rather than general psychosocial needs [21] and therefore this study identified information needs only within its sample. Specifically, a desire for information about whether treatment will work (63.1\%), the ability to have children (62.5\%) and paying for care (59.2\%) were the three most highly rated informational needs. As these two studies are so different in terms of the type of need that they assessed for, it is difficult to draw out any trends regarding needs relating to patients at this stage of illness. Both studies scored well on the quality assessment, indicating the findings to be reliable.

\section{Treatment}

Five studies assessed unmet psychosocial needs during active treatment [22-27]. Within this category, concerns about the worries of those close to patients was raised twice $[22,23]$, by $26 \%$ and $50 \%$ of respective samples; a third study highlighted family-oriented needs as the area associated with the highest levels of unmet need at both whole-sample and lymphoma sub-sample level of analysis [24]. Fear of recurrence was highlighted as an unmet need by three of the included studies $[22,23$, 26]. Most of these papers did not separate participant responses according to diagnosis bar the study conducted by Liang [24]. This study found that patients with lymphoma reported higher levels of need in the areas of 'sex' and 'work' than other participants and reported the lowest levels of needs in relation to 'stress'. Results from a mixed samples 
undergoing treatment also highlighted the need for patients to fully understand their diagnosis and the possible side effects of treatment [25].

\section{End of Treatment}

Only one study was identified at this time-point [28]. The needs assessment tool used within the study was one developed specifically for use within the study and so is not necessarily straightforwardly compared with other research. Fatigue (78\%) and anxiety (77\%) were the highest rated areas of need within the sample.

\section{Mixed Time-points}

Six studies assessed need in participants who were at different timepoints in their experiences of cancer [6, 29-34]. Four of these six studies used the Patient Needs Inventory (PNI) to assess need in their samples [6, $30,31,33,34]$. In these, needs relating to healthcare professionals were ranked highly, with $94 \%$ and $88.8 \%$ of patients identifying confidence in healthcare professionals as being important to them [31, 33]. Of the two papers that used measures other than the PNI, one used the Supportive Care Needs Survey (SCNS-SF34)[29] and the other the Patient Information Need Questionnaire (PINQ) [32]. The study that used the SCNS-SF34 highlighted lack of energy/tiredness, not being able to do the things you used to, and fears about the cancer spreading as the most commonly reported. Mesters et al [32] used a tool that assessed information needs only and reported that those relating to information about treatment and disease were most common, reflecting the findings from the study by Jenkins [35]. It is of note that psychological needs were raised in the 
McDowell study only [29], however this does not necessarily indicate the lack of needs in this area in the remaining studies, rather that the measures selected were not designed to adequately highlight these needs.

Results of studies assessing unmet psychosocial needs in haematology only samples

\section{Treatment}

Only one study was identified that assessed need during treatment in a haematology specific sample [36]. This study used the CaSUN to assess need in patients being treated for myeloma and found that the most commonly reported needs were either practical or psychological, with fear of recurrence being highlighted (7.9\%) as a prominent unmet need. This reflects findings reported in research using mixed samples. Other needs identified within this study were more accessible hospital parking (10.6\%), help with life or travel insurance (10.4\%), an ongoing case manager (7.4\%) and help to reduce stress (6.6\%).

\section{End of Treatment}

The one paper identified at this time-point [37] was unique in recruiting patients with any haematological diagnosis rather than restricting to specific categories of haematological diagnoses. The most frequently reported unmet need was help to manage concerns about the cancer coming back (42\%), followed by the need for an on-going case manager (33\%) and the need to know that doctors talk to each other to coordinate my care $(31 \%)$. 
Follow-up Care

There was just one paper that was found to assess need in participants during the follow-up phase [38]. This study looked specifically for the presence of unmet information needs relating to fertility and sexual functioning and found that in young people, 61\% expressed the need for more information about fertility issues. 


\section{Discussion}

\section{General trends in type and prevalence of unmet needs}

Across both the mixed and haematology only samples, fear of recurrence emerged as an unmet need. Unmet information needs were also raised within both samples, however the area in which information was felt to be required differed between studies. The two longitudinal studies included in this review indicated that the level of unmet needs present decreased over time $[20,22]$, however in a sub-group of patients, the presence of unmet needs persists well beyond the initial diagnosis phase. It is especially pertinent to note that reported needs varied somewhat based on the type of needs assessment tool used.

Six studies used either the SCNS $[20,22,23,29]$ or the CaSUN $[36,37]$ as assessment tools: these measures are used repeatedly in psychosocial need research [13]. In all six of these studies, unmet psychological needs (in particular fear of recurrence) emerged distinctly as the most endorsed category of unmet need. Given that these tools are so endorsed, the evidence provided for the prevalence of unmet psychosocial need seems irrefutable. Both of the studies to use the CaSUN also scored highly in the quality assessment, at $95.4 \%$ and $100 \%$, further indicating the reliability of these findings.

Four studies used the PNI to assess unmet need; this measure does not have a sub-section for psychological need which may have decreased the number of times that this was identified; those studies that did assess for this type of need report that patients consistently rate it highly. Within 
those studies that assessed need using the PNI, unmet needs relating to health professionals were scored most highly with levels as high as $94 \%$ $[6,30,31,33,34]$. Information needs were also common [21, 25, 32, 33], however, this may be due to the type of need that some studies assessed for.

In comparison with a previously published review on unmet supportive care needs across all cancer diagnoses [13], this review has highlighted some important differences. The Harrison review found the most commonly identified unmet need to be in the domain of activities of daily living, a clear difference from the prominence of fear of recurrence, a psychological need, found in this review. It is possible that this difference results from this review focusing specifically on patients with a haematological diagnosis and that psychological needs are of greater importance to this patient group. This assumption is supported by the fact that all studies conducted with a haematological sample that assessed for fear of recurrence, found it to be rated as important to their sample. In addition, a recent report by the Department of Health (2012) [39]found that, in comparison to patients with breast, prostate or colorectal cancers, patients with a haematological malignancy indicated the higher levels of difficulty associated with both anxiety and with planning for the future. This further supported the supposition that patients with haematological cancer have greater levels of need in the psychological domain. 
Secondary to fear of recurrence, needs relating to information were also identified in five studies, however, the specific type of informational need did vary between studies due to the differences in the ways in which items on assessment tools were phrased. The data would seem to indicate that fertility issues are important to this patient group, albeit there was limited data on this topic. In women with breast cancer, more information regarding fertility and menopause have been found to be desired [40] with younger women generally being more likely to report needs of this type [41], as was the case in this review. Information-related psychosocial needs have received a noteworthy amount of research interest within the wider cancer population $[42,43]$. Previous systematic reviews in the area, all with general cancer samples, have found that the most commonly reported information needs were related to treatment [44], although, like in this review, it was the case that the majority of papers included in the review focussed specifically on information needs at diagnosis and treatment, influencing the type of needs identified. The most common source of information was from healthcare professionals, giving depth to the identified need within this review to have confidence in healthcare professionals alongside the need for information. It has been argued that information provision for cancer patients needs to be responsive to patient need and preference and that relevant information can impact upon a patient's broader experiences of their illness [45].

\section{How do needs differ in the haematology sample?}

This review highlights the lack of research centred on identifying need in haematological cancer patients. Despite similarities between the 
haematology and general cancer groups, there were also differences found in the type of need identified at each of the time-points examined. At diagnosis, the mixed sample highlighted unmet needs that were psychological, however, the lack of haematology only studies at this timepoint meant that it was not possible to form any direct comparisons. At the treatment time-point, practical needs, fear of recurrence and psychological needs were clearly highlighted as a concern for the haematology samples at this time-point but not the mixed sample. Additionally, 'concerns about those close to you' was repeatedly expressed in the mixed sample studies but were not highlighted in the haematology only study, despite the assessment tool used asking about this issue. At the end of treatment, the primary reported unmet need in the haematology only paper was fear of recurrence; in the mixed sample paper however, fatigue and anxiety were also raised. While there was only one paper at this time-point for both samples, it does give an indication that psychological needs are important here.

The data also indicates that fertility issues are important to haematology patients, as raised in the studies by Hawkins and colleagues [21] and Hammond and colleagues [38]. There were differences in the exact need identified - being able to have children [21] and the need for more information about fertility issues [38], - although the overarching theme of fertility is shared. The differences in the precise need identified could be attributed however, to the way in which the two studies phrased their questions. As the studies were conducted in differing clinical groups, there is the potential for differences to emerge as a result of clinical 
variable rather than being caused by differences in the information provided to these samples. Given the nature of the samples being assessed, the presence of fertility related needs may seem unsurprising. The Hammond study [38] highlighted that younger people are more likely to express concern, that is the group of people most likely to have not yet had children. Regardless, it is still important that such needs are highlighted and recognised within the literature so as to create a solid evidence base from which services can draw and to ensure that such needs are known by all within the field.

None of the haematology specific studies were longitudinal in design, making it difficult to draw comparisons with findings from the mixed sample studies with regard to decreasing level of unmet need over time. Previous work [13] has found that levels of unmet needs were highest during treatment, lending support to the finding from this review that needs decrease as time passes, however, the same review noted that a greater number of individuals were likely to express unmet needs posttreatment than any other time. It is possible, therefore, that people generally have fewer overall needs as time since diagnosis passes but that there are other periods where patients are likely to need support, the period after the completion of treatment where patients transition towards survivorship self-management being likely. It is also important to note that a decrease in the number of needs does not necessarily correlate with a decrease in the saliency of the remaining needs. A single need in the follow-up care phase may be more likely to cause distress and impact upon quality of life than multiple unmet needs during treatment; the 
saliency of the need is a key issue here, but one that is less easy to predict [46]. In both studies included within this review that assess need at the end of treatment $[28,37]$, psychological needs were noted suggesting the presence of longer-term emotional needs.

\section{Limitations}

Psychological needs emerged as a key unmet need in the mixed cancer samples, however, due to the assessment tools used, it is not possible to determine from this which aspect of psychological wellbeing participants felt was not adequately being met. The study conducted by Liang et al [24] assessed for psychological need as a single type of unmet need and Boyes et al [20] reported their results as 'needs within the psychological domain' but did not specify further as to what those needs were. We therefore recognise the relevance of this category to those with a diagnosis of haematological cancer but it is not clear when needs are classified in this way what exactly it is that participants were meaning when they identified psychological needs as being important to them, limiting the clinical utility of the finding.

There were variations in the type of unmet needs identified, which may be attributed to differences between the ways in which unmet needs were assessed. Of the 18 papers included within the review, there were 11 different needs assessment tools used. Different tools mean differences in the ways in which needs are classified which will impact upon the types of needs identified. Even where needs appear to fall within the same category, differences in the way that needs are categorised limit the 
generalisability of the results. For example, both psychological needs and fear of recurrence were highlighted within the results. Within the literature, fear of recurrence is classed as a psychological need but when a paper uses an assessment tool that simply asks participants whether or not they have any psychological needs, it is unclear how participants define this. Additionally, some papers chose to focus their investigations upon a specific aspect of psychosocial need, for example information needs, meaning that this was the only category of need identified within that paper. This has meant that some areas of need were being commonly identified within this review but it is not known whether they would have the same prominence had all studies assessed needs in a more consistent manner.

A weakness of the evidence to come out of this review is that, although the review focuses on needs in haematological cancer, only three studies were found that looked solely at this patient group. There were no studies identified in either sample group that looked at needs in the follow-up care phase, meaning that there is no research evidence looking at long term unmet needs in patients with haematological cancer; with the growing importance of cancer survivorship, this gap in the literature needs to be addressed[3]. There are some similarities when studies are grouped according to diagnosis and time-point, however, no single group contains more than six studies. These relatively small sample sizes mean that generalizability of the results drawn from these groups is limited. 
Overall, the quality scores of the included research were high, with an average quality score of $83.4 \%$ lending credence to our findings with three studies receiving full marks of $100 \%$. The lowest score awarded was $54.5 \%$ [23]. This study was one of six that assessed need during the treatment phase in mixed cancer samples where three studies achieved a quality score of over $90 \%$ which goes some way to balance this lower quality score and limiting the impact that a lower score may have upon our findings. Generally across our sample, weaknesses were found in sample sizes and in response rates rather than in the innate design of the research.

The diversity within the group of disorders categorised as haematological cancers must also be recognised. As a first review of unmet need within haematological cancer, we have simply tried to assess the existing literature to provide a baseline for further research on unmet need within this patient group. It is highly likely that type of need will differ according to diagnosis given the innate differences between them and this is an important differentiation for future research to make.

\section{Implications for future research and practice}

The aim of this systematic review was to gather together existing literature relating to unmet psychosocial needs in those with haematological cancer. The hope was that this would enable a clearer understanding of the type of need that is most relevant to this patient group. Isolating key areas of need is the critical first step in the creation of effective support services. This review has indicated that psychological 
needs are currently unmet for a significant proportion of this patient group. Healthcare professionals working with this patient group should be aware of the type of psychosocial need most commonly experienced by their patients; this review suggests that fear of recurrence, the desire for information and positive relationships with those involved in their care are all of importance and should be kept in mind. Moving forward, more efficient targeting and provision of services that meet these needs should be viewed as a key aim for healthcare services in the future. Future research would benefit from both more work looking at haematological patients only and at their specific needs and from more studies that evaluate type and prevalence of need over time since diagnosis. Additionally, this study has highlighted weaknesses in the existing needs assessment tools in current use. The SCNS provides a wide ranging assessment of need and appears to target key areas of need, however, based upon the limited evidence relating to needs in haematology, more investigation is needed to determine the most appropriate method of assessment for this patient group. 


\section{Acknowledgments}

BS designed the study, conducted the systematic review, analysed the data and drafted the review.

NHW designed the study, contributed to the interpretation of the data and critically revised drafts of the review.

RB designed the study, contributed to the interpretation of the data and critically revised drafts of the review.

\section{Conflict of Interests}

There are no conflicts of interest to declare. The authors have full control of all primary data and consent for the journal to request this data if required. 


\section{References}

1. Bensing, J., Bridging the gap. The separate worlds of evidence-based medicine and patient-centered medicine. Patient Education and Counseling, 2000. 39(1): p. 17-25.

2. Holland, J., M. Watson, and J. Dunn, The IPOS New International Standard of Quality Cancer Care: integrating the psychosocial domain into routine care. Psycho-Oncology, 2011. 20(7): p. 677-680.

3. Watson, E.K., et al., Personalised cancer follow-up: risk stratification, needs assessment or both? British Journal of Cancer, 2012. 106(1): p. 1-5.

4. Carlson, L.E., A. Waller, and A.J. Mitchell, Screening for Distress and Unmet Needs in Patients With Cancer: Review and Recommendations. Journal of Clinical Oncology, 2012. 30(11): p. 1160-1177.

5. Sanson-Fisher, R., et al., The unmet supportive care needs of patients with cancer. Cancer, 2000. 88(1): p. 225-236.

6. Mclllmurray, M.B., et al., The psychosocial needs of cancer patients: findings from an observational study. European Journal of Cancer Care, 2001. 10(4): p. 261-269.

7. Bonevski, B., et al., Evaluation of an instrument to assess the needs of patients with cancer. Cancer, 2000. 88(1): p. 217-225. 
8. Wen, K.G., D. , Needs assessment for cancer patient and their families. Health and Quality of Life Outcomes, 2004. 2: p. 11.

9. Puts, M.T.E., et al., A pilot study on frailty, health and functioning in older newly-diagnosed cancer patients, what have we learned? Journal of Geriatric Oncology, 2011. 2(4): p. 246-252.

10. Hodgkinson, K.B.P.H.G.E.P.S.H.K.M.L.S.K.W.G., The development and evaluation of a measure to assess cancer survivors' unmet supportive care needs: the CaSUN (Cancer Survivors' Unmet Needs measure). Psycho-Oncology, 2007. 16(9): p. 796-804.

11. Minstrell, M., et al., Supportive care of rural women with breast cancer in Tasmania, Australia: changing needs over time. Psycho-Oncology, 2008. 17(1): p. 58-65.

12. Hemingway, H. and M. Marmot, Evidence based cardiology - Psychosocial factors in the aetiology and prognosis of coronary heart disease: systematic review of prospective cohort studies. British Medical Journal, 1999. 318(7196): p. 1460-+.

13. Harrison, J.D., et al., What are the unmet supportive care needs of people with cancer? A systematic review. Supportive Care in Cancer, 2009. 17(8): p. 1117-1128.

14. Howell, D.A., et al., Haematological malignancy: are patients appropriately referred for specialist palliative and hospice care? A systematic review and meta-analysis of published data. Palliative Medicine, 2011. 25(6): p. $630-641$.

15. Sherman, R.S., E. Cooke, and M. Grant, Dialogue among survivors of hematopoietic cell transplantation: Support-group themes. Journal of Psychosocial Oncology, 2005. 23(1): p. 1-24. 
16. Paul, C.L., et al., Cutting the research pie: a value-weighting approach to explore perceptions about psychosocial research priorities for adults with haematological cancers. European Journal of Cancer Care, 2011. 20(3): p. 345-353.

17. Ernst, J.C., et al., Use and need for psychosocial support in cancer patients. Cancer, 2013. 119(12): p. 2333-2341.

18. Howie, J.G.R., et al., Quality at general practice consultations: cross sectional survey. British Medical Journal, 1999. 319(7212): p. 738-743.

19. Macmillan, Cancer clinical nurse specialists: An evidence review. 2011.

20. Boyes, A., et al., Does routine assessment and real-time feedback improve cancer patients' psychosocial well-being? European Journal of Cancer Care, 2006. 15(2): p. 163-171.

21. Hawkins, N.A., et al., Informational needs of patients and perceived adequacy of information available before and after treatment of cancer. Journal of Psychosocial Oncology, 2008. 26(2): p. 1-16.

22. Armes, J., et al., Patients' Supportive Care Needs Beyond the End of Cancer Treatment: A Prospective, Longitudinal Survey. Journal of Clinical Oncology, 2009. 27(36): p. 6172-6179.

23. Clavarino, A.M., et al., The needs of cancer patients and their families from rural and remote areas of Queensland. The Australian journal of rural health, 2002. 10(4): p. 188-95.

24. Liang, L.P., et al., IDENTIFYING PRIORITIES OF PSYCHOSOCIAL NEED IN CANCER-PATIENTS. British Journal of Cancer, 1990. 62(6): p. 1000-1003.

25. Jenkins, V., L. Fallowfield, and J. Saul, Information needs of patients with cancer: results from a large study in UK cancer centres. British Journal of Cancer, 2001. 84(1): p. 48-51. 
26. Preyde, M., et al., Exploratory Survey of Patients' Needs and Perceptions of Psychosocial Oncology. Journal of Psychosocial Oncology, 2010. 28(3): p. 320-333.

27. Sollner, W., et al., How successful are oncologists in identifying patient distress, perceived social support, and need for psychosocial counselling? British Journal of Cancer, 2001. 84(2): p. 179-185.

28. Ashbury, F.D., et al., A Canadian survey of cancer patients' experiences: Are their needs being met? Journal of Pain and Symptom Management, 1998. 16(5): p. 298-306.

29. McDowell, M.E., et al., Predictors of change in unmet supportive care needs in cancer. Psycho-Oncology, 2010. 19(5): p. 508-516.

30. Mclllmurray, M.B., et al., Psychosocial needs in cancer patients related to religious belief. Palliative Medicine, 2003. 17(1): p. 49-54.

31. Soothill, K., et al., The significant unmet needs of cancer patients: probing psychosocial concerns. Supportive Care in Cancer, 2001. 9(8): p. 597-605.

32. Mesters, N., et al., Measuring information needs among cancer patients. Patient Education and Counseling, 2001. 43(3): p. 253-262.

33. Soothill, K., et al., The universal, situational, and personal needs of cancer patients and their main carers. European journal of oncology nursing : the official journal of European Oncology Nursing Society, 2003. 7(1): p. 5-13; discussion 14-6.

34. Soothill, K., et al., Grouping cancer patients by psychosocial needs. Journal of Psychosocial Oncology, 2004. 22(2): p. 89-109.

35. Jenkins, V., L. Fallowfield, and J. Saul, Information needs of patients with cancer: results from a large study in UK cancer centres. The British Journal of Cancer, 2001. 84(1): p. 48-51. 
36. Molassiotis, A., et al., Unmet supportive care needs, psychological wellbeing and quality of life in patients living with multiple myeloma and their partners. Psycho-Oncology, 2011. 20(1): p. 88-97.

37. Lobb, E.A., et al., When the safety net of treatment has been removed: Patients' unmet needs at the completion of treatment for haematological malignancies. Patient Education and Counseling, 2009. 77(1): p. 103-108.

38. Hammond, C.T.C., et al., Non-Hodgkin's lymphoma survivors' fertility and sexual function-related information needs. Fertility and Sterility, 2008. 90(4): p. 1256-1258.

39. Health, D.o., Quality of life of cancer survivors in England: Report on a pilot survey using patient reported outcome measures (PROMS). 2012.

40. Thewes, B., et al., Fertility- and menopause-related information needs of younger women with a diagnosis of early breast cancer. Journal of Clinical Oncology, 2005. 23(22): p. 5155-5165.

41. Vivar, C.G. and A. McQueen, Informational and emotional needs of longterm survivors of breast cancer. Journal of Advanced Nursing, 2005. 51(5): p. 520-528.

42. van Mossel, C., et al., Information needs across the colorectal cancer care continuum: scoping the literature. European Journal of Cancer Care, 2012. 21(3): p. 296-320.

43. Vitinius, F., et al., Psychosocial strain and information needs of patients with prostate cancer - A systematic review. Journal of Psychosomatic Research, 2012. 72(6): p. 507-508.

44. Finney Rutten, L.J., Arorab, N., Bakosc, A.D, and N.R. Azizb, J., Information needs and sources of information among cancer patients:

a systematic review of research (1980-2003). Patient Education and Counseling, 2005. 57: p. 250-261. 
45. Kazimierczak, K.A.e.a., Provision of cancer information as a "support for navigating the knowledge landscape": Findings from a critical interpretive literature synthesis. European journal of oncology nursing, 2012. 17 (3): p. 1-10.

46. Morrison, V., et al., Common, important, and unmet needs of cancer outpatients. European Journal of Oncology Nursing, 2012. 16(2): p. 115123.

Figures 
Figure 1: Flow diagram of inclusion assessment 
Table

\begin{tabular}{|c|c|c|c|c|c|c|c|c|}
\hline Author & Year & Country & Measure & Sample size & $\begin{array}{l}\% \\
\mathrm{~s} \\
\mathrm{a} \\
\mathrm{m} \\
\mathrm{p} \\
\mathrm{I} \\
\mathrm{e} \\
\mathrm{h} \\
\mathrm{a} \\
\mathrm{e} \\
\mathrm{m} \\
\mathrm{a} \\
\mathrm{t} \\
\mathrm{o} \\
\mathrm{I} \\
\mathrm{o} \\
\mathrm{g} \\
\mathrm{y}\end{array}$ & $\begin{array}{l}\text { Haematological } \\
\text { diagnoses included }\end{array}$ & \begin{tabular}{l|l} 
A Quality assessment \\
v score (\%) \\
e \\
r \\
a \\
g \\
e \\
\\
a \\
g \\
e
\end{tabular} & $\begin{array}{l}\text { Key } \\
\text { Findings } \\
\text { as } \\
\text { Reported } \\
\text { in Paper }\end{array}$ \\
\hline \multicolumn{9}{|l|}{$\begin{array}{l}\text { Diagnos } \\
\text { is }\end{array}$} \\
\hline $\begin{array}{l}\text { Boyes et } \\
\text { al }\end{array}$ & 2006 & Australia & SCNS & 80 & $\begin{array}{l}\mathrm{c} \\
\mathrm{o} \\
\mathrm{n}\end{array}$ & Lymphoma & \begin{tabular}{l|l}
9 & 92.3 \\
5 & \\
$0 \%$ & \\
& \\
0 & \\
$v$ & \\
$e$ & \\
$r$ & \\
4 &
\end{tabular} & $\begin{array}{l}\text { Psychologi } \\
\text { cal needs } \\
\text { most } \\
\text { commonly } \\
\text { reported. }\end{array}$ \\
\hline
\end{tabular}




\begin{tabular}{|c|c|c|c|c|c|c|c|c|}
\hline & & & & & $\begin{array}{l}\mathrm{g} \\
\mathrm{r} \\
\mathrm{o} \\
\mathrm{u} \\
\mathrm{p}\end{array}$ & & 0 & \\
\hline $\begin{array}{l}\text { Hawkins } \\
\text { et al }\end{array}$ & 2008 & USA & $\begin{array}{l}\text { Designed } \\
\text { for study }\end{array}$ & 731 & $\begin{array}{l}7 \\
6\end{array}$ & Unclear & \begin{tabular}{l|l}
6 & 81.8 \\
1 &
\end{tabular} & $\begin{array}{l}\text { Informatio } \\
\mathrm{n} \text { needs in } \\
\text { areas of } \\
\text { social, } \\
\text { lifestyle } \\
\text { and } \\
\text { financial } \\
\text { concerns } \\
\text { identified. } \\
\text { Also } \\
\text { required } \\
\text { more } \\
\text { informatio } \\
\mathrm{n} \\
\text { regarding } \\
\text { long-term } \\
\text { implication } \\
\text { s. }\end{array}$ \\
\hline \multicolumn{9}{|l|}{$\begin{array}{l}\text { Treatme } \\
\text { nt }\end{array}$} \\
\hline $\begin{array}{l}\text { Armes et } \\
\text { al }\end{array}$ & 2009 & UK & SCNS & 1152 & 5 & $\overline{\mathrm{NHL}}$ & \begin{tabular}{l|l}
6 & 90.1 \\
0 & \\
8 & \\
8 & \\
( & \\
$\mathrm{h}$ & \\
$\mathrm{a}$ & \\
$\mathrm{e}$ & \\
$\mathrm{m}$ & \\
\end{tabular} & $\begin{array}{l}66 \% \\
\text { expressed } \\
\text { few or no } \\
\text { needs at } \\
\text { T0, } 69 \% \\
\text { expressed } \\
\text { few or no } \\
\text { needs at } \\
\text { T1. Most } \\
\text { frequently }\end{array}$ \\
\hline
\end{tabular}




\begin{tabular}{|c|c|c|c|c|c|c|c|c|}
\hline & & & & & & & $\begin{array}{l}5 \\
5 \\
. \\
5 \\
)\end{array}$ & $\begin{array}{l}\text { reported } \\
\text { needs at } \\
\text { both time } \\
\text { points } \\
\text { were } \\
\text { psychologi } \\
\text { cal needs } \\
\text { and fear of } \\
\text { recurrence. }\end{array}$ \\
\hline $\begin{array}{l}\text { Clavarino } \\
\text { et al }\end{array}$ & 2002 & Australia & SCNS & 28 & 4 & Leukaemia & \begin{tabular}{l|l}
4 & 54.5 \\
3 & \\
. & \\
6 &
\end{tabular} & $\begin{array}{l}\text { Psychologi } \\
\text { cal needs } \\
\text { most } \\
\text { commonly } \\
\text { reported. } \\
\text { Fear of } \\
\text { recurrence } \\
(42.9 \%) \\
\text { and } \\
\text { concerns } \\
\text { about the } \\
\text { worries of } \\
\text { those close } \\
\text { to you } \\
\text { (50\%) } \\
\text { most } \\
\text { common } \\
\text { unmet } \\
\text { needs in } \\
\text { patient } \\
\text { group }\end{array}$ \\
\hline $\begin{array}{l}\text { Jenkins } \\
\text { et al }\end{array}$ & 2001 & UK & $\begin{array}{l}\text { Adaptation } \\
\text { of } \\
\text { Cassilth's } \\
\text { Informatio } \\
\text { n Needs }\end{array}$ & 2331 & $\begin{array}{l}7 \\
8 \\
8\end{array}$ & Unclear & \begin{tabular}{l|l}
7 & 95.4 \\
0 & \\
$\%$ & \\
0 &
\end{tabular} & $\begin{array}{l}87 \% \\
\text { preferred } \\
\text { to have as } \\
\text { much } \\
\text { informatio }\end{array}$ \\
\hline
\end{tabular}




\begin{tabular}{|c|c|c|c|c|c|c|c|c|}
\hline & & & $\begin{array}{l}\text { questionna } \\
\text { ire }\end{array}$ & & & & $\begin{array}{l}\mathrm{v} \\
\mathrm{e}\end{array}$ & $\begin{array}{l}\mathrm{n} \text { as } \\
\text { possible. }\end{array}$ \\
\hline $\begin{array}{l}\text { Liang et } \\
\text { al }\end{array}$ & 1990 & Australia & $\begin{array}{l}\text { Designed } \\
\text { for study }\end{array}$ & 188 & 8 & Lymphoma & \begin{tabular}{l|l}
5 & 81.8 \\
2 &
\end{tabular} & $\begin{array}{l}\text { Family was } \\
\text { reported } \\
\text { as the } \\
\text { highest } \\
\text { need, } \\
\text { followed } \\
\text { by dealing } \\
\text { with } \\
\text { emotional } \\
\text { stress. }\end{array}$ \\
\hline $\begin{array}{l}\text { Molassiot } \\
\text { is et al }\end{array}$ & 2011 & UK & CaSUN & 132 & $\begin{array}{l}1 \\
0 \\
0\end{array}$ & Multiple myeloma & \begin{tabular}{l|l}
6 & 100 \\
2 &
\end{tabular} & $\begin{array}{l}\text { Highest } \\
\text { reported } \\
\text { need was } \\
\text { for more } \\
\text { accessible } \\
\text { hospital } \\
\text { parking, } \\
\text { followed } \\
\text { by } \\
\text { insurance } \\
\text { and then } \\
\text { fear of } \\
\text { recurrence. }\end{array}$ \\
\hline $\begin{array}{l}\text { Preyde et } \\
\text { al }\end{array}$ & 2010 & Canada & $\begin{array}{l}\text { ESAS, CES- } \\
\text { D and } \\
\text { Perceived } \\
\text { Social } \\
\text { Support } \\
\text { Scale }\end{array}$ & 156 & \begin{tabular}{|l}
2 \\
3
\end{tabular} & Unclear & \begin{tabular}{l|l}
6 & 63.6 \\
1 &
\end{tabular} & $\begin{array}{l}\text { Fear of } \\
\text { recurrence } \\
\text { main need } \\
\text { identified. }\end{array}$ \\
\hline
\end{tabular}




\begin{tabular}{|c|c|c|c|c|c|c|c|c|}
\hline $\begin{array}{l}\text { End of } \\
\text { treatme } \\
\text { nt }\end{array}$ & & & & & & & & \\
\hline $\begin{array}{l}\text { Ashbury } \\
\text { et al }\end{array}$ & 1998 & Canada & $\begin{array}{l}\text { Designed } \\
\text { for study }\end{array}$ & 913 & $\begin{array}{l}1 \\
1\end{array}$ & Lymphoma & \begin{tabular}{l|l}
7 & 63.6 \\
6 & \\
$\%$ & \\
$o$ & \\
$v$ & \\
$e$ &
\end{tabular} & $\begin{array}{l}\text { Fatigue } \\
\text { and } \\
\text { anxiety } \\
\text { most } \\
\text { commonly } \\
\text { reported } \\
\text { symptoms. }\end{array}$ \\
\hline $\begin{array}{l}\text { Lobb et } \\
\text { al }\end{array}$ & 2009 & Australia & CaSUN & 113 & $\begin{array}{l}1 \\
0 \\
0\end{array}$ & All & \begin{tabular}{l|l}
5 & 95.4 \\
4 &
\end{tabular} & $\begin{array}{l}\text { Most } \\
\text { frequently } \\
\text { endorsed } \\
\text { need was } \\
\text { the need } \\
\text { to feel as } \\
\text { though I } \\
\text { am } \\
\text { managing } \\
\text { my health } \\
\text { together } \\
\text { with the } \\
\text { medical } \\
\text { team, the } \\
\text { most } \\
\text { frequent } \\
\text { unmet } \\
\text { need was } \\
\text { fear of } \\
\text { recurrence. }\end{array}$ \\
\hline
\end{tabular}




\begin{tabular}{|c|c|c|c|c|c|c|c|c|}
\hline \multicolumn{9}{|l|}{$\begin{array}{l}\text { Follow- } \\
\text { up Care }\end{array}$} \\
\hline $\begin{array}{l}\text { Hammon } \\
\text { d et al }\end{array}$ & 2008 & USA & $\begin{array}{l}\text { Informatio } \\
\mathrm{n} \text { needs } \\
\text { questionna } \\
\text { ire }\end{array}$ & 250 & \begin{tabular}{l|}
1 \\
0 \\
0
\end{tabular} & Aggressive NHL & \begin{tabular}{|l|l}
$y$ & 68.2 \\
$n$ & \\
$r$ & \\
$e$ & \\
$p$ & \\
0 & \\
$r$ & \\
$t$ & \\
$e$ & \\
$d$ &
\end{tabular} & $\begin{array}{l}61 \% \text { of } \\
\text { young } \\
\text { people } \\
\text { expressed } \\
\text { the need } \\
\text { for } \\
\text { informatio } \\
\text { n about } \\
\text { fertility. }\end{array}$ \\
\hline \multicolumn{9}{|l|}{\begin{tabular}{|l|} 
Mixed \\
time- \\
points
\end{tabular}} \\
\hline $\begin{array}{l}\text { McDowell } \\
\text { et al }\end{array}$ & 2010 & Australia & SCNS-SF34 & 438 & $\begin{array}{l}\mathrm{U} \\
\mathrm{n} \\
\mathrm{c} \\
\mathrm{I} \\
\mathrm{e} \\
\mathrm{a} \\
\mathrm{r}\end{array}$ & Unclear & \begin{tabular}{|l|l|}
5 & 90.1 \\
9 & \\
2 & \\
3 & \\
\end{tabular} & $\begin{array}{l}\text { Unmet } \\
\text { needs } \\
\text { decrease } \\
\text { over time } \\
\text { since } \\
\text { diagnosis. } \\
\text { Unmet } \\
\text { needs at } \\
\text { diagnosis } \\
\text { predict } \\
\text { later } \\
\text { presence } \\
\text { of unmet } \\
\text { needs. }\end{array}$ \\
\hline $\begin{array}{l}\text { Mclllmurr } \\
\text { ay et al }\end{array}$ & $\begin{array}{l}2001 / 20 \\
03\end{array}$ & UK & PNI & 402 & $\begin{array}{l}1 \\
5 \\
. \\
4 \\
2 \\
2 \\
\end{array}$ & Lymphoma & \begin{tabular}{|l|l|}
5 & 100 \\
9 & \\
$\%$ & \\
& \\
0 & \\
$v$ & \\
\end{tabular} & $\begin{array}{l}\text { Needs } \\
\text { relating to } \\
\text { health } \\
\text { profession } \\
\text { als most } \\
\text { commonly }\end{array}$ \\
\hline
\end{tabular}




\begin{tabular}{|c|c|c|c|c|c|c|c|c|}
\hline & & & & & $\begin{array}{l}8 \\
8 \\
5 \\
5 \\
7\end{array}$ & & \begin{tabular}{l|}
$\mathrm{e}$ \\
$\mathrm{r}$ \\
6 \\
0 \\
0
\end{tabular} & $\begin{array}{l}\text { expressed. } \\
\text { Informatio } \\
\mathrm{n} \text { and } \\
\text { support } \\
\text { networks } \\
\text { also } \\
\text { common } \\
\text { areas. }\end{array}$ \\
\hline $\begin{array}{l}\text { Mesters } \\
\text { et al }\end{array}$ & 2001 & $\begin{array}{l}\text { Netherla } \\
\text { nds }\end{array}$ & PINQ & 498 & $\begin{array}{l}4 \\
3 \\
. \\
3 \\
7 \\
3 \\
4 \\
9 \\
3 \\
9 \\
8\end{array}$ & Hodgkin's Lymphoma & \begin{tabular}{l|l}
$y$ & 90.1 \\
$n$ & \\
$k$ & \\
$n$ & \\
0 & \\
$w$ & \\
$n$ &
\end{tabular} & $\begin{array}{l}\text { A need for } \\
\text { informatio } \\
\mathrm{n} \text { about } \\
\text { disease } \\
\text { and } \\
\text { treatment } \\
\text { was the } \\
\text { strongest } \\
\text { theme. }\end{array}$ \\
\hline $\begin{array}{l}\text { Soothill } \\
\text { et al }\end{array}$ & 2001 & UK & PNI & 295 & \begin{tabular}{|l|}
5 \\
8
\end{tabular} & Lymphoma & \begin{tabular}{l|l}
4 & 72.3 \\
4 & \\
$\% / p$ & \\
$u$ & \\
$n$ & \\
$d$ & \\
$e$ & \\
$r$ & \\
6 & \\
0 &
\end{tabular} & $\begin{array}{l}4.4 \% \text { of } \\
\text { sample } \\
\text { had } 10+ \\
\text { significant } \\
\text { unmet } \\
\text { needs. } \\
\text { Confidence } \\
\text { in } \\
\text { healthcare } \\
\text { profession } \\
\text { als most } \\
\text { commonly } \\
\text { rated as } \\
\text { important } \\
\text { or very } \\
\text { important. }\end{array}$ \\
\hline
\end{tabular}




\begin{tabular}{|c|c|c|c|c|c|c|c|c|}
\hline & & & & & & & & $\begin{array}{l}\text { Most } \\
\text { common } \\
\text { unmet } \\
\text { needs } \\
\text { were help } \\
\text { with } \\
\text { financial } \\
\text { matters, } \\
\text { help filling } \\
\text { out forms, } \\
\text { help with } \\
\text { anger and } \\
\text { opportuniti } \\
\text { es to meet } \\
\text { people in } \\
\text { the same } \\
\text { situation. }\end{array}$ \\
\hline $\begin{array}{l}\text { Soothill } \\
\text { et al }\end{array}$ & 2003 & UK & PNI & 233 & $\begin{array}{l}\mathrm{U} \\
\mathrm{n} \\
\mathrm{r} \\
\mathrm{e} \\
\mathrm{p} \\
\mathrm{o} \\
\mathrm{r} \\
\mathrm{t} \\
\mathrm{e} \\
\mathrm{d}\end{array}$ & Lymphoma & \begin{tabular}{l|l}
6 & 77.2 \\
0 & \\
$\dot{3}$ & \\
&
\end{tabular} & $\begin{array}{l}\text { Most } \\
\text { common } \\
\text { patient } \\
\text { reported } \\
\text { unmet } \\
\text { needs: } \\
\text { help with } \\
\text { financial } \\
\text { matters; } \\
\text { help filling } \\
\text { out forms; } \\
\text { help with } \\
\text { dealing } \\
\text { with anger. } \\
\text { Majority of } \\
\text { patient- } \\
\text { carer pairs } \\
\text { expressed }\end{array}$ \\
\hline
\end{tabular}




\begin{tabular}{|c|c|c|c|c|c|c|c|c|}
\hline & & & & & & & & $\begin{array}{l}\text { importance } \\
\text { of good } \\
\text { relationshi } \\
\text { ps with } \\
\text { healthcare } \\
\text { profession } \\
\text { als and } \\
\text { good } \\
\text { quality } \\
\text { informatio } \\
\text { n. }\end{array}$ \\
\hline $\begin{array}{l}\text { Soothill } \\
\text { et al }\end{array}$ & 2004 & UK & PNI & 380 & $\begin{array}{l}\mathrm{U} \\
\mathrm{n} \\
\mathrm{c} \\
\mathrm{I} \\
\mathrm{e} \\
\mathrm{a} \\
\mathrm{r}\end{array}$ & Lymphoma & \begin{tabular}{l|l}
$y$ & 86.4 \\
$n$ & \\
$c$ & \\
l & \\
$e$ & \\
$a$ & \\
$r$ &
\end{tabular} & $\begin{array}{l}\text { Found that } \\
\text { patterns of } \\
\text { psychosoci } \\
\text { al need } \\
\text { differ } \\
\text { between } \\
\text { distinct } \\
\text { patient } \\
\text { groups. }\end{array}$ \\
\hline
\end{tabular}

Table I: Table to summarise key information from included studies. 
